\title{
A percepção da saúde mental de uma estudante de psicologia: narrativa autobiográfica
}

\author{
The perception of mental health in a psychology \\ student: autobiographical narrative
}

\section{Rebecca Conceição Ferreira Aquino' ${ }^{1}$ Mônica Ramos Daltro² Mayara Margarida Santos Muniz ${ }^{3}$ (1)}

\author{
1Escola Bahiana de Medicina e Saúde Pública (Salvador). Bahia, Brasil. rcfaquino18@outlook.com \\ ${ }^{2}$ Autora para correspondência. Escola Bahiana de Medicina e Saúde Pública (Salvador). Bahia, Brasil. monicadaltro@bahiana.edu.br \\ ${ }^{3}$ Centro Universitário UniFTC (Feira de Santana). Bahia, Brasil. mayarapsi@yahoo.com.br
}

\begin{abstract}
RESUMO | Estudar Psicologia se constitui numa experiência psiquicamente mobilizadora. O processo formativo coloca estudantes, em sua maioria, ainda adolescentes, ou jovens, precocemente expostos a conteúdos acadêmicos diretamente ligados à subjetividade humana e a cenários de práticas que envolvem o encontro com a dor e angústia de existir e viver em sociedade. Neste contexto, o estudante é atravessado por experiências que podem vir a afetar a sua saúde mental e promover sofrimento psíquico. O presente estudo tem como objetivo relatar a vivência acadêmica e seu impacto na saúde mental de uma estudante universitária, a partir de uma narrativa autobiográfica. A narrativa autobiográfica é uma técnica de construção de narrativa científica que a partir de um merguIho interior, relata um processo de elaboração da vivência que resulta numa teorização sobre uma experiência em estudo e realiza-se como prática transformar para conhecer. Assim, a pesquisa descreve os atravessamentos subjetivos de uma jovem estudante de Psicologia de uma instituição privada de ensino superior. Propõe-se a articular a experiência à teoria e analisa alguns efeitos da formação profissional e da constituição de identidade da estudante. A partir do relato, destaca-se a importância da garantia de espaços de fala e de cuidado no âmbito da formação em Psicologia, além do desenvolvimento de ações que acolham o sofrimento do mesmo.
\end{abstract}

PALAVRAS-CHAVE: Autobiografia. Psicologia. Estudante universitário. Saúde mental.

\begin{abstract}
Studying psychology is a psychically mobilizing experience. The formative process places students, most of them, still adolescents, or young people, early exposed to academic contents directly linked to human subjectivity and to practical scenarios that involve encountering the pain and anguish of existing and living in society. Consequently, the student is exposed to situations that may affect their mental health and trigger psychological distress. The present study is an autobiographical narrative guided by cartography that has the primary outcome of reporting the academic experience of a university student and the impact of this journey on her mental health. The use of cartography allows writing to be used as a strategy of self-development to promote selfawareness by enabling the subjective study of the being. Herein, this study analyzes the effect of the academic exposure on the student's professional formation and identity construction. In this context, it is paramount to ensure selfcare, open communication environments and development of coping strategies to assist on the students suffering during the process of training in psychology.
\end{abstract}

KEYWORDS: Autobiography. Psychology. University student. Mental Health. 


\section{Introdução}

A Organização Mundial de Saúde (OMS) define saúde não apenas como a ausência de doença, mas como a situação de perfeito bem-estar físico, mental e social. Sendo assim, a saúde mental passa ser um elemento deste grande leque, considerada um estado de bem-estar, no qual o individuo percebe seu próprio potencial, lida com as questões normais da vida, pode trabalhar de forma produtiva e é capaz de contribuir para sua comunidade (Oku, Oku, Owoaje \& Monjok, 2015). Os problemas na saúde mental podem surgir a partir do momento em que ocorre o desequilíbrio entre o patrimônio interno e as exigências ou vivências externas, resultando em uma luta para lidar com os desafios e responsabilidades da vida (Oku et al., 2015).

A saúde mental dos estudantes universitários vem sendo estudada no Brasil, de maneira mais formal, desde a década de 1950. Entretanto, até a atualidade ainda existem poucos estudos nacionais que investiguem o caráter de risco das vivências acadêmicas para a saúde mental do aluno. De acordo com Igue, Bariani e Milanesi (2008) existe um grande número de estudos internacionais sobre o impacto da experiência acadêmica. Entretanto, na literatura encontrada, são poucas as pesquisas referentes especificamente aos estudantes de Psicologia.

Antes composta majoritariamente por uma população branca, de classe média alta e alta, a universidade brasileira mudou, assim como o perfil do estudante. As políticas públicas de expansão de acesso ao ensino superior imprimiram novos contornos identitários. Neste contexto, o qual metade dos estudantes de universidades federais brasileiras passaram a ser oriundos de classes populares, a saúde do estudante se apresentou como uma questão que precisa ser compreendida a partir da interação entre as demandas do processo de graduação e os aspectos sociais, econômicos e pessoais (Oliveira \& Padovani, 2014). Esse cenário político ampliou também o acesso dos estudantes a instituições privadas de ensino superior onde, também foi colocado, o desafio de compreender melhor esse novo perfil.

A vivência como estudante universitário está estatisticamente associada ao final da adolescência e início da idade adulta. Para Papalia e Feldman (2006) o ingresso na Universidade é caracterizado por mudanças significativas e complexas na forma como o estudante pensa em diferentes áreas de suas vidas, podendo se desenvolver intelectualmente e pessoalmente. É nesse contexto de vida que, associado com as preocupações relacionadas ao curso, o indivíduo geralmente experimenta indefinições relacionadas a escolhas futuras (Levandowski \& Da Luz, 2006). Teixeira, Castro e Piccolo, (2007 como citado em Cardoso, Garcia, Fernanda, 2015) reafirmam a importância de estudos para compreender esta população, que ao entrar na universidade, depara-se com grandes mudanças em seu cotidiano, na medida em que "trata-se de um marco na vida desse individuo, que acessa um universo acadêmico, depara-se com novas normas, diferentes metodologias de ensino, de funcionamento de grupos e se expõe a um grande e diversos número de pessoas " (Cardoso, Garcia \& Schroder, 2015).

Esse ambiente rico, diverso e produtivo pode ser também nocivo à saúde mental dos estudantes, especialmente se não há condições e normas adequadas que viabilizem o desenvolvimento saudável da socialização, induzam e facilitem a comunicação de alunos com professores, pais, famílias e com a sociedade, bem como suas relações ambientais (Padovani \& Oliveira, 2014). Entretanto, dificuldades adaptativas são também referenciadas à essa etapa de transição entre o ensino médio e o ingresso no ensino superior, experiência que pode ser considerado como estressora pelo desafio de construir novas formas de socialização com novos colegas e professores, novas regras, assim como novos conteúdos didáticos que exigem destes estudantes maior autonomia e responsabilidades.

Alain Coulon (2008), um etnógrafo francês, realizou uma investigação na Universidade Paris VIII, que evidenciou os ritos próprios ao ingresso no contexto universitário que se realizam a partir da construção de esquemas culturais, os quais possibilitam ao estudante apreender o universo cultural universitário até que possa se tornar nativo a este. Para o autor, antecedendo ao processo de aprendizagem, sobre a profissão escolhida, o estudante necessita afiliar-se à instituição, de forma a perceber-se como parte daquele universo e ocupar-se do que denomina de Ofício de Estudante. Destaca nesse contexto o papel de políticas institucionais e das relações interpessoais como suporte a essa experiência, especialmente se originada do corpo docente (Coulon, 2008). 
De acordo com Mercuri e Polydoro (2004), o ambiente acadêmico favorece diversas mudanças durante o processo de adaptação e de formação, propriamente dito, as quais englobam a aprendizagem e formação, os níveis de autonomia, as habilidades cognitivas, as motivações, o desempenho acadêmico, o desenvolvimento psicossocial e as expectativas quanto à inserção no mercado de trabalho já nos últimos anos da universidade. Todos esses processos se relacionam com a formação da identidade e amadurecimento pessoal e profissional nas relações com familiares, colegas e profissionais (Cardoso, Garcia \& Schroder, 2015). Assim, as exigências e demandas da vida universitária deixam evidente que o aluno, desde o seu ingresso, deve apresentar recursos cognitivos e emocionais complexos para o manejo das demandas deste novo ambiente (Bonifácio, Silva, Montesano \& Padovani, 2011).

Além disso, uma vez que a escolha de uma carreira exige o estabelecimento de um planejamento profissional em relação às expectativas futuras, o cenário do mercado de trabalho torna-se uma variável importante, que pode tornar mais difícil esse processo, em casos onde a profissão apresenta poucas oportunidades de trabalho. Desse modo, a ausência de oportunidades profissionais poderá provocar um sentimento ambíguo no estudante quanto ao caminho a ser seguido (Levandowski \& Da Luz, 2006).

Complementando essa ideia, Padovani e Oliveira (2014) afirmam que, no público universitário, ao se levar em consideração as elevadas expectativas, as exigências referentes ao mundo e ao mercado de trabalho, assim como as expectativas pelo futuro profissional e pessoal, normalmente encontra-se uma alta prevalência de problemas psicoafetivos, os quais muitas vezes são desconhecidos. Essa falta de conhecimento pode acarretar uma desvalorização de certos sintomas ou até mesmo um tratamento inadequado.

Destacam-se aqui as especificidades do contexto que envolve o estudante universitário da área de saúde. Além das demandas inerentes a este novo ambiente acadêmico, eles passam a lidar com cenários de práticas desafiadores, onde entram precocemente em contato com angustias, dores e anseios de pacientes e seus familiares. Nesse universo, estão os estudantes de Psicologia, expostos a teorias mobilizadoras em si e ao contato direto com o sofrimento psíquico de outras pessoas além da exposição permanente a conteúdos acadêmicos de natureza complexa e relacionados com a subjetividade humana (Andrade, Antunes \& Zanoto, 2016). Sendo assim, faz-se necessário discutir singularidades da vivência acadêmica no âmbito da formação em Psicologia articuladas à questão da saúde mental do estudante universitário.

\section{Metodologia}

Trata-se de uma pesquisa de abordagem qualitativa autobiográfica, que visa discutir a experiência no ensino superior a partir de um relato singular de uma estudante universitária. em uma instituição privada de ensino superior em Salvador-Bahia, a partir de uma metodologia autobiográfica.

A descrição da experiência acadêmica da autora - escrita a partir da primeira pessoa do singular descreve um processo vivido entre os anos de 2014 a 2019, na Escola Bahiana de Medicina e Saúde Pública (que chamarei a partir de agora simplesmente de Bahiana). Instituição vocacionada para a saúde com 67 anos de tradição na formação de profissionais de saúde no Estado da Bahia.

O curso de Psicologia com 19 anos de reconhecimento e aprovação pelo Ministério da Educação (MEC), tendo formado aproximadamente 1500 psicólogos, exibe uma estrutura curricular moderna, com o uso de metodologias ativas e estrutura voltada para o desenvolvimento de competências para uma atuação generalista, além de afirmar a Psicologia como uma profissão de saúde. O modelo curricular adota como referência a concepção de saúde ampliada e seus princípios como referência para o desenvolvimento do trabalho pedagógico. Seu currículo está afirmado como um território dialógico, e, portanto, como um campo onde estão presentes contradições, tensionamento e deslocamentos que dão vida ao exercício formativo (Daltro \& Pondé, 2017).

Diante a escolha da metodologia norteadora do trabalho, é importante salientar que o relato de experiência é uma importante narrativa cientifica. Esta se trata de um estudo do grau de certeza do conhecimento científico em seus diversos ramos, expandido a partir das singularidades, o que a faz uma importante ferramenta científica na atualidade. Isso se justifica devido à junção entre teoria e prática, o que se dispõe a construção de saberes referentes à experiência em si (Daltro \& de Faria, 2019). 
Tal construção tem origem através da perspectiva do pesquisador em um determinado contexto a nível cultural e histórico. Não há a intenção de se constituir como algo restrito, fechado, ou que estabeleça uma verdade absoluta, mas sim a procura de saberes inovadores (Daltro \& de Faria, 2019) e perspectivas singulares referidas ao desafio da experiência de formação em Psicologia em um contexto social, político e estético da contemporaneidade.

O presente trabalho utiliza a narrativa autobiográfica na construção metodológica, técnica na qual o narrado se coloca a serviço da pesquisa tal qual a pesquisa se coloca à serviço do narrado, na medida em que sua construção se faz a partir de um mergulho interior, processo de rememoração e consequente elaboração trata-se de um modelo de pesquisa que em si, provoca mudanças na forma como as pessoas compreendem a si próprias e às experiências em análise produzindo, a partir desse processo, uma teorizando a própria experiência. Assim, possibilita o estudo de objetos de caráter subjetivo, ela busca a própria escrita como prática de transformar para conhecer. Neste formato de investigação, o sujeito e objeto estão juntos na mesma experiência e a pesquisa tem caráter de intervenção que gera conhecimento. Ou seja, refere-se a uma trajetória de autoria do corpo, das sensações, de percursos de um corpo no encontro das experiências de sensibilidade com o mundo (Silva \& Daltro, 2018).

Inspirado na cartografia, que pode ser definida como uma ciência geográfica que produz e estuda mapas de territórios, esse trabalho apresenta justamente uma experiência territorializada no cerne de seu processo analítico. Territórios podem se referir às questões mais subjetivas, existenciais, afetivas, éticas, entre outros. No âmbito da pesquisa, a cartografia tem crescido consideravelmente, porque permite vastas possibilidades de análise ao favorecer seu uso por parte do pesquisador em qualquer realidade, onde envolva análise de fenômenos complexos ou o objetivo analítico seja acompanhar processos (Costa, 2014).

Seguindo este método, a experiência em elaboração foi construída uma linha de tempo-vida entre os anos de 2014 a 2019, descrevendo as memórias afetivas, atitudinais e de conhecimento durante o processo da graduação da aluna, para que desta forma fosse feita a articulação da experiência subjetiva com a teoria.

\section{Resultados e discussões}

\section{0 ingresso no ensino superior}

Quando fui aprovada no vestibular, não esperava que o inicio da graduação fosse trazer tantas mudanças na dinâmica da minha vida. Apesar de já estar a cinco meses morando em Salvador e tendo uma rotina completamente diferente do que estava acostumada - passei a morar com a minha prima, precisava cumprir além das obrigações de estudo, as obrigações de casa - a passagem para o nível superior carregava muitos significados; e apesar de sempre ter demonstrado uma personalidade desapegada, estava muito assustada diante de todas essas mudanças.

Será que eu me tornaria adulta assim que pusesse os pés na Bahiana? Será que os meus colegas me aceitariam e eu teria muitos amigos? Será que a minha escolha pela Psicologia estava "correta"? Ou será que eu deveria ter ouvidos conselhos da minha mãe e ter feito medicina (pois, segundo a ela, eu teria um retorno financeiro garantido)? Enfim, esses eram alguns dos muitos questionamentos que passavam pela minha cabeça.

Embora seja preciso considerar a necessidade de adaptação decorrente da transição dos modos de aprender e ensinar do ensino médio para o ensino superior, faz-se necessário considerar, que na minha experiência, estava também em jogo a transição da adolescência para a fase adulta, cenário que deu ao ingresso na universidade uma marca transformadora.

A fase adulta da vida, tem seu início contemplado entre os 20 e os 40 anos e define-se, sobretudo, pela ascensão de tarefas psicossociais às quais culturalmente tem-se a expectativa de que o indivíduo adulto seja capaz de desempenhar, como o ingresso no mercado de trabalho, a independência financeira, a saída da casa dos pais e o estabelecimento de uma relação conjugal estável. É nesse contexto de vida que, associado com as preocupações relacionadas ao curso, o 
indivíduo geralmente experimenta indefinições a escolhas futuras (Levandowski \& Da Luz, 2006). Na minha experiência, me perguntava se poderia ser psicóloga, já que ainda não era adulta?

\section{Os primeiros dias de aula}

Existia um misto de ansiedade, medo, dúvida, curiosidade e, principalmente, muita expectativa sobre esse novo lugar! No meu primeiro dia de aula, percebi que, de fato, a minha vida estava mudando, eu me sentia sozinha e sentia que tudo que acontecesse dali pra frente dependeria de mim. Apesar de ser algo comum na rotina de muitas pessoas, pegar o meu primeiro ônibus sozinha causou-me certa apreensão. Mas apesar dessa sensação, decidi encarar. Segui todas as instruções que a minha prima tinha me passado, porém nem tudo saiu como o previsto. Perdi o ônibus certo e acabei chegando atrasada no meu primeiro dia de aula. Passei o caminho todo até à Bahiana aflita, odiava chegar atrasada nos lugares e ser o centro das atenções, mas precisei vencer minha timidez e pela segunda vez no dia, enfrentar os meus medos.

No decorrer da manhã, fui tentando me ambientar e me aproximar de pessoas que, para mim, tinham o mesmo estilo que eu. Eu já havia conhecido uma colega durante a Vivência do Processo Seletivo Formativo realizado pela Bahiana no qual somos apresentados a um dos campus da Bahiana e somos convidados a refletir sobre a escolha do curso através de Dinâmicas de Grupo que também possibilitam conhecer os futuros colegas. Lembro que em uma das Dinâmicas a pergunta disparadora era sobre o motivo da escolha pela Psicologia. Bem, eu realmente não sabia o que responder. $\mathrm{E}$ até chegar a minha vez, eu fiquei martelando na minha cabeça o que poderia dizer ou não. Eu sabia que uma parcela de mim escolheu o curso porque acompanhar o processo depressivo da minha mãe foi muito doloroso, outra parte escolheu porque todos os meus amigos sempre falaram que eu era boa em ouvir as pessoas e outra parte porque eu sempre estive atenta e observando o que estava ao meu redor. Mas, naquele momento, nenhuma dessas justificativas passavam pela minha cabeça, era um grande vão. E para ser sincera, eu não lembro o que eu respondi. Era psicologia porque tinha que ser naquele momento, e que bom que foi!
A minha vivência, está em acordo com os estudos nacionais que afirmam que a escolha pela Psicologia como profissão, está frequentemente alicerçada em motivações de natureza predominantemente interna, como o desejo de ajudar de compreender as pessoas e suas formas de sofrer ou no desejo de conhecer o outro e a si mesmo. Fatores como mercado de trabalho, potência de remuneração, carreira ou reconhecimento social, são secundarizados (Bastos \& Gondim, 2010).

A inserção dos jovens na vida acadêmica é algo que causa grandes mudanças nas suas vidas. A migração é um ponto importante nessa nova fase, uma vez que o jovem, em alguns casos, precisa deixar sua cidade natal, casa e família para ingressarem em uma carreira de nível superior. Sendo assim, a migração pode impactar fortemente a nível físico e psíquico, visto que o estudante passa a imergir em um universo novo, além da saudade da família, pressão pela necessidade de ter um bom desempenho acadêmico, dificuldades financeiras e de estabelecimento de relações e vínculos com indivíduos novos, são alguns dos fatores que podem causar, além de outras coisas, um alto grau de estresse e ansiedade nos jovens, além de outras coisas (Bonifácio et al., 2011).

Foi o que aconteceu comigo, um grande deslocamento subjetivo. Mas no início, nem eu sabia o tamanho disso. Deparei-me com uma nova rotina, novas responsabilidades, prazos para cumprir, habilidades para desenvolver e novas pessoas para conquistar.

Como havia passado no vestibular do meio do ano, a minha turma era menor e apresentava grande diversidade, incluindo gênero, classe social e idade. Apesar dessas diferenças, percebia que a maioria deles demonstravam as mesmas expectativas e anseios que eu. Nos primeiros dias, todos estavam bem próximos, andávamos em um grande grupo, conversamos entre os intervalos das aulas e com o passar das semanas as famosas panelinhas foram se formando. O que pra mim era muito comum, acredito que em todos os lugares com muitas pessoas, existe uma tendência a vínculos criados pelas características em comum. 


\section{Os primeiros semestres}

A rotina do primeiro semestre era tranquila, tínhamos matérias introdutórias, como Filosofia, Sócioantropologia, Fundamentos de Psicologia, Processos Psicossociais e Saúde, Metodologia Instrumental e o Desenvolvimento do Ciclo de Vida 1(DCV). Essa última apresentava uma dinâmica diferente, que era Problem Based Learning - PBL (Aprendizagem Baseado em Problemas) - é uma metodologia de aprendizado autodirigida, centrado no estudante. Ou seja, deslocávamos do ensino tradicional transversal para o ensino horizontal, onde nós mesmos éramos responsáveis em gerar conhecimento. A turma era dividida em tutorias e os encontros aconteciam às segundas e sextas-feiras. Trabalhávamos em uma perspectiva da resolução de casos, identificando o problema e criando objetivos para "solucioná-lo". Também elegíamos o coordenador, que tinha a função de conduzir a tutoria, e o relator, responsável por registrar os pontos importantes discutidos.

O método da Aprendizagem Baseada em Problemas (ABP) propõe que os alunos discutam e resolvam situações-problemas relacionadas à sua futura atuação profissional e, partir disso construir conhecimento, desenvolver autonomia e criticidade em relação aos conteúdos abordados (Sampaio, Queiroz, 2019).

Quando essa nova metodologia foi exposta, eu fiquei muito surpresa, pois fugia de tudo que eu já havia vivenciado em anos de estudo. Não sabia o que esperar e a ansiedade falou mais alto. Por ser muito tímida, sempre tive dificuldade de falar em público, ainda mais quando eu não poderia decorar o que deveria falar no momento; não era como apresentação de trabalhos, era uma construção grupal do saber e os meus colegas também precisariam da minha contribuição. Eu não sabia se eu conseguiria. Durante a semana me dediquei a fazer a pesquisa, me apeguei a alguns pontos que pudessem me ajudar a desenvolver o pensamento na hora, mas não estudei para que de fato tivesse segurança.

Então, o dia do fechamento de caso chegou, começamos a tutoria revisando os objetivos e aos poucos meus colegas iam contribuindo com suas pesquisas individuais. O tempo foi passando e eu não conseguia falar nada, não encontrava uma brecha em que pudesse trazer algum ponto para discussão, e fui ficando cada vez mais desconfortável naquele espaço.
Me sentia oprimida, incapaz e culpada. Eu poderia ter estudado mais. Naquele momento eu não poderia fazer mais nada, aceitei que não falaria naquela primeira semana, mas algo que eu não esperava aconteceu. Minha tutora direcionou a fala para mim, eu fiquei perdida, em pânico, não sabia o que fazer... acabei lendo um parágrafo aleatório de um dos pontos que tinha selecionado. Pode ter sido impressão, mas eu sentia o julgamento dos meus colegas e isso não me fez bem. Sai da minha primeira tutoria arrasada, me questionando se conseguiria seguir.

Apesar de não ter sido o que eu esperava, essa primeira experiência de tutoria fez com que eu compreendesse como as coisas funcionariam dali para frente. Percebi que precisava me dedicar mais aos estudos, para que tivesse propriedade e não fosse mais doloroso o processo de desenvolvimento da fala em público. Destaco isso como um ponto positivo, pois pude perceber que era capaz de sair da minha zona de conforto e oferecer mais do que eu estava acostumada. Acho importante citar também que existia uma certa necessidade de imposição e competição da fala durante as tutorias entre os meus colegas. Tentei não me ater ao fato, mas era inevitável não me cobrar durante esse processo. Porque, além disso, eu precisava cumprir e desenvolver as competências, habilidades teóricas e atitudinais do componente curricular.

Com essa experiência, destaco aqui novamente o estudo realizado por Alain Coulon (2008), o qual traz que ao ingressar o ensino superior, o aluno deve aprender a tornar-se estudante, no sentido etnológico do termo. Ou seja, deverá descobrir e se apropriar da rotina que envolve novas regras e códigos do mundo universitário. Na presença de tantas mudanças é necessário que o estudante desenvolva novos modos de fazer, que incluem interações com os outros, desde uma simples saudação até discussões elaboradas sobre todos os assuntos e opiniões.

Os novos modos de fazer dizem respeito à definição da etnometodologia retrabalhada por Coulon (2008), que é o estudo do que as pessoas sabem sobre o que eles fazem e sobre as consequências de suas ações. Relacionando este conceito ao estudante universitário, podemos perceber que é necessário que o indivíduo reconheça as inúmeras mudanças pertencentes à aquele espaço, para que o mesmo possa aprender 
a funcionar dentro daquele grupo social e afiliar-se ao mesmo. Visto que, os estudantes que não conseguem se afiliar a esse novo mundo se encontram rapidamente em situação de fracasso. Logo, é necessário que aprendam seu ofício de estudante.

Além dessa dimensão sociológica, os teóricos do desenvolvimento afirmam que a exposição ao ambiente educacional-cultural da universidade se converte, cognitivo e socialmente em uma experiência de amadurecimento. Isso porque expõe o jovem à contextos teóricos-vivenciais que possibilitam a problematização de verdades construídas em ambientes familiares e escolares e indicam a existência de realidades mais complexas relacionadas ao mundo dos adultos. Concomitantemente, o funcionamento cognitivo se desloca, progride de uma lógica mais rígida para uma maior flexibilidade. Em lugar de verdades absolutas emerge a possibilidade de reconhecimento da existência de pontos de vistas distintos, diversos e menos idealizados (Papalia \& Olds, 2000).

Diante de todas essas questões e novidades para lidar, estar na universidade era algo satisfatório. Comecei a notar que era muito mais interessante ser aluna do curso de Psicologia do que aluna do curso pré-vestibular; era muito gratificante ter 17 anos e já estar no segundo semestre da faculdade. Eu sentia falta de apoio emocional dos meus pais, mas me sentia independente e dona da minha vida. Aquilo dependia de mim, e eu estava decidida a fazer da melhor forma possível. Como já havia dito anteriormente, a rotina do primeiro semestre foi leve em questão de conteúdos e exigências, acredito que a mudança maior estava ligada a novos posicionamentos, atitudes e rotina.

O início do segundo semestre chegou e com eles novas mudanças. Nossa grade tinha uma nova estrutura, os horários estavam preenchidos das 7 horas às 13 horas e as matérias eram mais demandantes, pois tínhamos seminários, trabalhos escritos, provas, além dos casos semanais da tutoria. Diante todas essas atividades, percebi que precisava dedicar mais tempo à faculdade. Esse semestre foi como um balde de água fria, era comum ouvir comentários de que "quem passa pelo segundo, passa por todos". E eu precisava concordar, estava sendo muito exaustivo.
Sustentar esse lugar não era fácil. Apesar de já estar integrada e adaptada ao dia-a-dia na Bahiana, algo em mim mudou. Mesmo com a rotina de cobranças do ensino médio, principalmente durante $o 3^{\circ}$ ano do ensino médio, sempre fui uma aluna mediana. Não tinha uma rotina assídua de estudos e não me importava em tirar notas baixas ou reprovar nas matérias. Entretanto, o ensino superior estava cheio de novas descobertas e repetir esse comportamento de descuido com os meus estudos soava absurdo. Não era a posição que eu queria ocupar. Por um lado, isso foi bom, porque eu pude perceber que era a única responsável pelo meu futuro como profissional, mas por outro lado eu fui ficando cada vez mais rigorosa comigo mesma. Apeguei-me a notas, desempenho máximo, escore e tudo que pudesse quantificar que eu estava sendo boa no papel de estudante universitária. Além disso, por mais contraditório que seja, era normal faltar aulas para colocar outras matérias em dias. Meus colegas, assim como eu, também repetiam esse comportamento.

Uma identidade de adulta nascia em mim e a saúde mental começou a ter novos sentidos. O processo de amadurecimento promove uma inteligência adulta, está associada à aquisição de conhecimentos, particularmente conhecimentos especializados e referidos a domínios específico; consideram que ser adulto na contemporaneidade é muito mais do que busca atingir a estabilidade na vida profissional, financeira e familiar, é colocar-se como perene aprendiz (Sousa, 2007), inserido no universo da linguagem, apto a simbolizar e a sofrer.

Byung-Chul Han, filosofo coreano, em seu livro "A Sociedade do Cansaço" traz a ideia do "doping cerebral" (o melhoramento cognitivo), este por sua vez, possibilita de certo modo o desempenho sem desempenho. Ou seja, a sociedade do desempenho e a sociedade ativa geram um cansaço e esgotamento excessivo. Esses estados psíquicos são característicos de um mundo que se tornou pobre em negatividade e que dominado pelo excesso de positividade (Han, 2017, p. 70). Refletindo sobre essa questão, pontuo que inconscientemente respondia a essa pseudo positividade, negligenciando e calando o meu sofrimento. 


\section{Práticas de cuidado}

Em todo esse movimento, não pude refletir o quanto esse deslocamento trazia impactos para a minha saúde mental. Só conseguia enxergar o meu lado proativo como algo positivo e isso era reforçado sempre. Os meus amigos e a minha família - apesar de não estar próxima fisicamente - elogiavam a minha dedicação e se orgulhavam da minha mudança.

A cobrança era maior por estar em uma área de saúde, ainda mais se tratando da profissão escolhida. Eu aprendia diariamente a como acolher a dor do outro. A formação era pautada no cuidado. Precisávamos estar atentos ao olhar, ao corpo e a fala; aprendíamos a observar e a escutar. Era necessário que desenvolvêssemos habilidades para compreender o sofrimento que não poderia ser tateado. Para lidar com isso, é necessário estar fortalecido psiquicamente. Nosso corpo é o nosso instrumento de trabalho. Logo, supõe-se que precisaríamos estar bem integralmente no conjunto dos aspectos biopsicossociais. Evidentemente, isto não seria possível e vale ressaltar, não havia sido posto como obrigação. Na verdade, é um pensamento utópico. Toda e qualquer pessoa está sujeita a sofrimento, inclusive estudantes de Psicologia.

Considerando este aspecto, um estudo realizado por Andrade, Antunes, Zanoto, Tiraboschi, Viana \& Curilla (2016) para fazer um levantamento sobre as vivências acadêmicas dos estudantes de Psicologia. Este concluiu que no que se refere à percepção geral das vivências do curso - incluindo opinião sobre a instituição e o curso, oportunidades de pesquisa, cidade da universidade, relacionamento interpessoal, entre outros - são aspectos amplamente favoráveis. Já em relação à vivência e o sofrimento psíquico, os estudantes destacam que as situações vividas são desfavoráveis - dentre elas: a carga horária excessiva, a grande quantidade de atividades avaliativas no fim do semestre, questões econômicas, situações de rupturas de vínculos, mudança de cidade, inserção institucional etc - Diante este cenário, nota-se que os estudantes do ensino superior são expostos a condições que podem vir a trazer sentimentos de inadequação e sofrimento psíquico.

Partindo desse ponto, é importante lembrar que é sugerido desde o início do curso que façamos acompanhamento psicoterápico individual simultaneamente com a faculdade, pois em muitos momentos somos expostos a conteúdos e falas de pacientes que podem falar de nós mesmos. Sendo assim, é extremamente importante que possamos acolher e trabaIhar nossas questões em outro espaço.

Mesmo diante deste cenário, eu me julguei capaz de passar sozinha - durante muito tempo - por essa graduação que trazia tantos desdobramentos, reflexões e angústias. Por um lado, estar exposta a estes conteúdos foi importante para que eu olhasse de outra forma para as questões intimas que me rodeavam, mas permaneciam no lugar de desconhecido. Por outro lado, até chegar a essa conclusão, eu passei por um grande processo de fuga do espaço acadêmico.

À medida que os semestres passavam, eu me percebia diferente naquele ambiente. Eu estava funcionando de forma automática, sem me deixar atravessar e me envolver nos conteúdos vistos. Era como se não me sentisse mais capaz de organizar meu tempo para realizar as atividades propostas. Então, atrasos e faltas tornaram-se recorrentes, assim como, a falta de interesse para os estudos individuais em casa.

Os modos de viver contemporâneo impõem aos jovens e adultos altos padrões de autogestão para lidar com os fluxos existenciais acelerados, o que promove diferentes impressões, sofrimentos e incertezas. Nesse contexto o adoecimento psíquico é sentido, mas nem sempre esse é reconhecido ou elaborado pelo sujeito social em questão. Observa-se certa falta de conhecimento sobre suas próprias emoções e afetos numa tentativa de produzir sujeitos homogêneos (Soares, 2018), os corpos são afetados. Dentro desta perspectiva Byung-Chul Han aborda sobre o "Yes, we can" (sim, nós podemos), como uma máxima que caracteriza o que ele chama de sociedade do desempenho, que se vale da positividade do sujeito como motivo para ação. Para o autor é sempre possível dar passos mais além e cabe ao sujeito gerir seu tempo (Han, 2017).

Apesar das crises de ansiedade, gastrite nervosa, alteração no sono, irritação e falta de prazer dentro do espaço acadêmico, durante um semestre inteiro eu insisti. Entretanto, com a chegada do internato, eu não me sentia mais capaz. Sabia que as práticas seriam mais diretas e estaríamos de fato em contato com o público em sofrimento. Em vista disso, não achei justo continuar, já que para cuidar do próximo, precisava primeiro cuidar de mim. Estava cansada, perdida, sufocada. Era nítido que precisava de um tempo para respirar e entender o que estava acontecendo comigo mesma. 
Greenberg, Carr e Summers (2002) apontam que a reação ao estresse pode ser dividida em três fases: alerta, resistência e exaustão. A primeira fase acontece quando a pessoa entra em contato com o agente estressor e seu corpo reage perdendo o equilíbrio natural. Em seguida, passando para a segunda fase, 0 organismo tenta reparar este equilíbrio, podendo se adaptar ao problema ou eliminá-lo. Na terceira fase, ocorre a falha nos mecanismos de adaptação ocasionando o déficit das reservas de energia.

Trazendo este conceito, Pinho Junior e Lipp (2003 como citado por Bonifácio, Silva, Montesano \& Padovani, 2011) mencionam que as doenças podem vir a aparecer em níveis físicos ou psíquicos, como por exemplo, úlceras, gengivites, hipertensão arterial, problemas dermatológicos, alergias, herpes, alterações no sono, cansaço mental, dificuldade de concentração e atenção, apatia e indiferença emocional. Ressaltam também que a produtividade e criatividade ficam prejudicadas, além de ser recorrente o desenvolvimento de crises de ansiedade e depressão. Todos esses aspectos afetam de forma significativa a qualidade de vida e a saúde mental do estudante dentro da universidade.

Apropriação do sofrer: assumir, cuidar e comunicar Não foi fácil admitir que eu precisava me distanciar naquele momento. Estava decepcionada por não conseguir atender ao papel de estudante universitária. Além do que, paralelo ao contexto acadêmico, eu também precisava lidar com a solidão em casa, as frustrações dos relacionamentos afetivos e as questões familiares desorganizadas. Era um cenário caótico gritando por socorro. Inúmeras incertas percorreram os meus pensamentos. Será que eu não tinha feito nada certo até ali? Será que eu não era mesmo capaz de estudar? Era um sentimento de fracasso misturado com culpa e a decisão de trancar o curso por um semestre foi dolorosa, mas necessária naquele momento.

Handke (1992 como citado por Han, 2017) contrapõe a ideologia do cansaço da sociedade do desempenho discutindo sobre um cansaço falaz e necessário: “Um cansaço como tornar-se acessível, sim, como plenificação do ser tocado e mesmo do poder tocar (...). O menos no eu se expressa como um mais para o mundo: “o cansaço era meu amigo. Eu estava ali de volta, no mundo." (Han, 2017, p. 73).
Percebo que apesar de acreditar que estava fazendo aquilo para entender o meu processo, posteriormente entendi que apenas queria ter um alívio momentâneo daquela situação. A transição ocorreu muito rápido e não tive tempo de estruturar todos aqueles novos modos de fazer do meu cotidiano.

O tempo que passei afastada da universidade foi positivo, mas talvez não suficiente. Morei com o meu pai durante quatro meses em São Paulo, me sentia cuidada e acolhida. Não ter obrigações o tempo todo me acalmava. Mas, sentia falta da minha privacidade, liberdade e em alguns momentos me sentia inútil por não possuir uma ocupação. Essas questões me fizeram refletir se de fato eu queria estar afastada da minha cidade, da universidade e dos meus amigos. Eu não tinha dúvidas em relação à escolha do curso, mas era angustiante pensar que voltaria às rotinas de estudos e às responsabilidades do dia-a-dia.

Eu retornei à Salvador decidida que retornaria para a universidade, porém com um novo posicionamento. Prometi que me cobraria menos e faria até onde fosse possível. Estar em uma nova turma facilitou o meu processo de reinclusão na rotina acadêmica, uma vez que pude conhecer novas pessoas e me estabelecer em um lugar que fosse confortável para mim. Por estarmos no internato - modelo de ensino que descreverei a seguir - nós ficávamos em grupos menores, o que ajudou a interação com meus novos colegas. A ansiedade que sentia no momento anterior ao internato foi brevemente cessada e estava feliz por estar de volta à minha rotina e ter as rédeas da situação.

Considero importante citar que, paralelo ao meu retorno à universidade, iniciei também a psicoterapia individual, isto foi de suma importância para que me desenvolvesse como pessoa e aprendesse uma forma de estar no espaço acadêmico respeitando minhas questões e acolhendo minhas dores e angústias.

A partir daí e compreendendo vivências acadêmicas não apenas como experiências intrapsíquicas, como se fora algo apenas da responsabilidade do estudante manter-se em bom estado de saúde mental e sucesso acadêmico, mas como referem Andrade et al. (2016) ao ampliar este entendimento, levam em consideração as vivências externas, dentre as quais o próprio contexto acadêmico em si e questões 
voltadas ao social que podem influenciar no bem-estar e desenvolvimento do estudante. Assim, diante da pesquisa realizada pelos autores, concluem a necessidade de apoio e assistência ao estudante diante do sofrimento psíquico.

A partir da importância do que Ramos, Jardim, Gomes e Lucas (2018) abordam da necessidade de acolher a demanda trazida pelo estudante a respeito do contexto acadêmico, com a finalidade de promover o apoio psicológico na universidade. Tal ação visa contribuir na minimização de adoecimentos e agravos, além de estimular o desenvolvimento de habilidades.

\section{O encontro com a prática}

Retornei no sétimo semestre desafiada a iniciar o internato. Baseado no modelo de ensino em medicina, o Curso de Psicologia da Bahiana criou o Internato. Trata-se de uma metodologia ativa de ensino que pressupõe uma aprendizagem construída a partir da articulação de conteúdos conceituais, técnicos e atitudinais seu objetivo principal é a aprendizagem em serviço, o aprender-a-refletir-fazendo. Diferencia-se das tradicionais experiências de estágio básico e estágio supervisionado em função do nível de complexidade das atividades desenvolvidas pelos estudantes e pelos docentes, o Internato configura-se como uma prática pedagógica assistida, na qual o professor está ao lado do aluno durante quase toda a experiência de aprendizagem. Além disso o Internato apresenta ao estudante formas de estar e atuar nos campos de prática, vinculados ao SUS, e promove o desenvolvimento de competências para uma atuação de generalista no estágio a partir da perspectiva da integralidade (Daltro \& Pondé, 2017)

O internato nos dava a chance de vivenciar quatro áreas da psicologia: ambulatorial, organizacional e do trabalho, hospitalar e em comunidade. Experienciar esses espaços foi de suma importância para entender o contexto das práticas e identificar com qual área eu me sentia mais confortável para exercer minha profissão. Desenvolvíamos atividades como acolhimentos, entrevistas, dinâmicas de grupo, acompanhamento de atendimentos de enfermagem e medicina, psicoprofilaxia, entre outros.
As minhas experiências do internato foram gratificantes e, apesar da insegurança por estar realizando novas atividades, me sentia satisfeita com o meu desempenho nas práticas. Não deixava de atender aos meus compromissos, mas também não negligenciava o meu bem-estar. Foi um ano tranquilo, que proporcionou aproximação com a Psicologia como profissão, assim como, a construção de novos ciclos de amizades, os quais em muitos momentos foram minha única rede de apoio.

\section{A vivência do estágio}

Com a chegada do estágio, novos desafios foram apresentados. Ainda que o internato nos desse a chance de experimentar diferentes campos, ainda não conseguia ter certeza de onde queria estar. Era uma escolha delicada, pois passaria um ano dentro de um espaço de trabalho e precisaria estar aberta a aprender uma nova dinâmica e estar imersa no desenvolvimento de habilidades práticas. Sem muita certeza, decidi que faria estágio em clínica ampliada, na clínica escola da universidade.

Articulando com o Yamamoto e Gouveia (2003), diante da heterogeneidade de campos da Psicologia, o discente confronta-se com a "necessidade de fazer escolhas quanto a sua futura área de atuação profissional" (p. XX). Sendo assim, ele busca dentre as áreas - clínica educacional, do esporte, organizacional e do trabalho, hospitalar, do trânsito - maior desenvolvimento teórico, metodológico e profissional por meio da prática no campo escolhido.

O estágio era dividido em atendimentos individuais na clínica e atendimentos grupais no ambulatório de psiquiatria. No inicio, era tudo muito novo e somos expostos a uma série de informações. Como a clínica funciona, horários de atendimento, divisão de pacientes para os grupos terapêuticos, escolha e apropriação da abordagem para nortear as práticas, e até algo comum que é realizar uma ligação, torna-se um evento repleto de significados.

O momento de ser psicóloga havia chegado e apesar de já estar a quatro anos dentro da universidade aprendendo conteúdos e técnicas que embasariam a 
minha prática, mais uma vez precisaria assumir um novo posicionamento. Novas regras e códigos são introduzidos na nossa rotina e faz-se necessário uma imersão neste novo espaço. Ressalto aqui que a passagem para o ambiente de trabalho, na posição de estagiária, é tão ansiogênica e potencializadora de crises quanto à chegada a universidade. Visto que, simultaneamente as responsabilidades do trabalho, precisamos lidar com a construção do Trabalho de Conclusão de Curso (TCC).

A respeito da inserção na prática de estágio e o quão ansiogênico pode ser sentido, é possível fazer uma relação ao que Padovani et al. (2014) comentaram sobre a inserção do estudante universitário, sobretudo os da área de saúde. Os autores referenciam que estes precisariam utilizar recursos cognitivos e emocionais mais complexos, haja vista as demandas do contexto de prática. Ainda nesse sentido, por meio do exercício, os estudantes se deparam com uma nova realidade, sendo por vezes depositários de angústias, expectativas de pacientes e familiares.

Andrade et al. (2016) afirmam que o contato com conteúdo de sofrimento de outras pessoas pode induzir o sofrimento psíquico no estudante, além de potencializar outros agravos.

Agulló-Tomás (1997 como citado por Melo \& Borges, 2007) traz uma discussão sobre o conceito de "ser jovem" na atualidade, visto que tal definição comporta vários critérios, como idade, status social, econômico e jurídico, além do contexto sociocultural". Sendo assim, torna-se incoerente "a unicidade do emprego do termo e amplia o risco do reducionismo conceitual". Ou seja, a juventude é um conceito aberto, construído a partir do processo histórico-cultural (Costa, 2000). Considera-se jovem aquele individuo que após ultrapassar a fase da adolescência "adquiriu condições necessárias, porém insuficientes, para o desempenho das funções de um adulto".

Costa (2000) relata que os jovens se diferenciam entre si, os jovens universitários durante a transição de estudante para profissional devem ser analisados como um grupo diferente dos outros, identificando as especificidades de sua inserção no mercado de trabalho e os desafios que enfrentam nesse contexto.
Durante a experiência do estágio me deparei com questões que envolviam o passado, o presente e o futuro, que precisavam ser acolhidas e trabalhadas para que eu pudesse concluir o ciclo da graduação. Ainda que eu estivesse identificada com o campo e mantivesse um bom relacionamento interpessoal, eu fui confrontada pelo medo e pela expectativa em relação à conclusão do curso e ao futuro no mercado de trabalho. Esse processo foi doloroso e, mais uma vez, foi difícil dar espaço ao adoecimento psíquico e solicitar ajuda das pessoas ao meu redor. Estar deprimida, como futura psicóloga, em uma clínica, dizia muito e a ideia de compartilhar isso me intimidava. Melo e Borges (2007) afirmam que:

O retardamento do ingresso no mercado de trabalho, para a continuação dos estudos, implica a permanência do status de jovem em virtude do adiamento da independência financeira, não sendo possível, então, encontrar todos os jovens dentro dos limites cronológicos estabelecidos pelos economistas (p.379).

A trajetória entre a universidade e o mundo do trabalho é um percurso central na construção da vida adulta. A perda da condição de estudante e do apoio do ambiente acadêmico é acompanhada pela perda da assistência da família, o desenvolvimento da identidade, a falta de status de trabalhador são alguns aspectos que podem vir a trazer sentimentos de insuficiência, fraqueza, insegurança, apatia e desorganização. Essa experiência demanda processos psíquicos adaptativos, processos de luto e elaboração e, portanto, podem promover processos de adoecimento, comportamentos antissociais ou fuga da realidade, caso a pessoa jovem não esteja sentindo-se apto e tenha recursos e apoio para deslocar-se para o espaço de cidadão ativo e produtivo dentro da sociedade. Portanto, por não haver outras formas de firmarem socialmente como adultos, os jovens da atualidade são aqueles que ainda buscam sua autonomia a partir da construção da identidade profissional, ou seja, sua independência financeira através da realização do trabalho (Melo e Borges, 2007).

Na minha experiência, estar fechando o ciclo da graduação trazia muitas indagações. O meu pai, minha família e eu mesma, inseridos culturalmente no que 
Han (2017) chamou de sociedade do desempenho, desenhavam um conjunto de cobranças, querendo saber sobre minha futura carreira, meus projetos, minhas possibilidades: referiam a mim como a mais nova psicóloga enquanto meus amigos afirmavam: Queria poder me formar tão nova como você. Ouvir esses questionamentos e afirmativas me impulsionavam, mas também paralisavam, e apesar de existir satisfação de ocupar esse espaço, a ansiedade de lidar com uma nova vida tomava conta. Eu estava me tornando adulta e isso demandaria que fosse responsável por mim, emocionalmente, socialmente e financeiramente. Existia o desejo de ocupar um lugar firme e sólido, mas também uma inércia de permanecer na mesma posição de jovem sem obrigações.

O encontro com a prática, foi fundamental nesse percurso, nos dias mais difíceis de existir, achei que desistiria, que não daria conta... mas ir para o estágio, ouvir as pessoas, ser vistas pelas pacientes como psicóloga, causava efeito de transformação em mim.

\section{O fim da graduação}

Então cheguei ao temido momento de fazer o Trabalho de Conclusão de Curso - TCC, afirmado pelos corredores, como uma experiência aterrorizadora. Passei a frequentar um grupo de pesquisa, me agreguei a uma pesquisa que pretendia estudar o universo psíquico dos estudantes de Psicologia, me comprometi a estudar a percepção dos estudantes sobre os efeitos dos cursos na sua saúde mental. Mas essa escolha foi atravessada pelo sofrimento psíquico, pela necessidade de interrupção do percurso, pela sensação de que não conseguiria dar conta de mim e nem da Psicologia.

Mas voltei e a proposta foi metodologicamente deslocada. Revisitar toda essa trajetória e escrever sobre ela fez com que eu contemplasse todo o meu processo de crescimento e percebesse o quanto o universo acadêmico nos convida a crescer e ocupar novos espaços. Em alguns momentos, foi angustiante recordar, elaborar e ressignificar determinadas passagens. Entretanto, afirmo a importância de registrar o conjunto de saber aprendido através do meu olhar de pesquisadora, descrevendo as verdades que impulsionaram novos cursos (Costa, 2014).

Considerando também que o desenvolvimento da escrita realiza-se no après coup, é necessário um momento de decantação e elaboração das vivências. Sua execução não tem pretensão totalizante ou epidemiológica, mas faz registro científico de uma narrativa que contempla um momento histórico, uma singularidade, combinada à de saberes teóricos (Daltro, Faria, 2019).

Finalizo este relato afirmando o que Coulon (2008) propõe, que quando entramos no ensino superior, na maioria das vezes, não temos noção das inúmeras mudanças que iremos vivenciar.

Durante cinco anos tenho vivido a Psicologia, aprendendo sobre ela e sendo atravessada por ela. Dediquei-me, me encontrei, me desencontrei, me achei de novo.... E em meio a tudo isso, um leque de transformações atravessou o meu corpo. Durante esse processo, me permiti sentir todas as angústias que cruzaram o meu caminho, para que eu pudesse não só aprender a Psicologia, mas também me desenvolver como pessoa adulta responsável pela minha trajetória.

A estrutura curricular encontrada, contribuiu para que eu pudesse olhar para o outro e para mim mesma, promovendo estratégias de cuidado e com cuidado, amor e acima de tudo respeito, sendo assim, é pertinente que façamos isso com nós mesmo.

Faz-se necessário compreender que a formação em Psicologia abraça, acolhe e ouve. A frase "nosso corpo é nossa casa e nossa mente é nosso lar", passou, de fato, a fazer sentido pra mim. O sofrimento existe e estar na universidade não oferece respostas, mas ajuda a compreender quais são as perguntas. Porém, diante de todo deslocamento e aprendizado, sintome transformada.

\section{Considerações finais}

O espaço acadêmico pode constituir como um potente território de mudança na vida da pessoa, proporcionar experiências que possibilitam não só formação profissional, mas também autoconhecimento e formação de identidade. Na experiência descrita, a vivência acadêmica se colocou como espaço de desenvolvimento de corpo e mente, isso porque permitiu aprender sobre a importância de se posicionar frente a uma perspectiva ética, de reconhecimento de si e do outro, respeitosa e colaborativa. 
A estrutura curricular foi também fundamental para uma experiência reflexiva, na medida em que se organizou de forma a promover desafios diários de vivências grupais e individuais, dentro e fora do contexto acadêmico. Nela, somos impulsionados aos questionamentos e às reflexões acerca do local de estudante universitária, adulta, que se pretende ser, assim como da responsabilidade quanto à construção do saber e da responsabilidade sobre o cuidado de si e o cuidado com o outro.

No processo de construção da identidade de psicóloga reconhecer a angústia como parte do processo pode ser promotor ou potencializador de sofrimento psíquico, mas também pode ser um caminho de ressignificação potente. Faz-se necessário discutir novas estratégias curriculares que criem espaço para discussão e manejo deste sofrimento, viabilizando a melhoria do bem-estar dentro do espaço acadêmico.

Esse artigo aborda a saúde mental como um fenômeno complexo, portanto coloca em circulação um saber legitimado pela vivência e reflexão sobre a experiência de tornar-se psicóloga. Não se pretende um estudo a ser generalizado, mais a produzir reflexões sobre as vicissitudes desse processo de formação que se abre como um campo a ser analisado em outras pesquisas que possam compreender essa complexidade, propondo novas alternativas teóricas, metodológicas e instrumentais.

\section{Contribuições das autoras}

Aquino RCF participou da concepção do projeto, coleta de dados e escrita do texto. Daltro MR participou da concepção do projeto, coleta de dados e escrita do texto. Muniz MMS participou da construção e escrita do texto.

\section{Conflitos de interesses}

Nenhum conflito financeiro, legal ou político envolvendo terceiros (governo, empresas e fundações privadas, etc.) foi declarado para nenhum aspecto do trabalho submetido (incluindo, mas não se limitando a subvenções e financiamentos, participação em conselho consultivo, desenho de estudo, preparação de manuscrito, análise estatística, etc.).

\section{Referências}

Andrade, A. S., Tiraboschi, G. A., Antunes, N. A., Viana, P. V. B. A., Zanoto, P. A., \& Curilla, R. T. (2016). Vivências Acadêmicas e Sofrimento Psíquico de Estudantes de Psicologia. Psicologia: Ciência e Profissão, 36(4), 831-846. https://dx.doi. org/10.1590/1982-3703004142015

Bastos, A. V., \& Gondim, S. M. G. (2010). O trabalho do psicólogo no Brasil. Artmed.

Bonifácio, S. P., Silva, R. C. B., Montesano, F. T., \& Padovani, R. C. (2011). Investigação e manejo de eventos estressores entre estudantes de Psicologia. Revista Brasileira de Terapias Cognitivas, 7(1), 15-20. http://pepsic. bvsalud.org/scielo.php?script=sci_arttext\&pid=S180856872011000100004\&lng=pt\&tlng=pt

Cardoso, L. M., Garcia, C. S., \& Schroeder, F. T. (2015). Vivência acadêmica de alunos ingressantes no curso de Psicologia. Psicologia Ensino \& Formação, 6(2), 5-17. http://pepsic. bvsalud.org/scielo.php?script=sci_arttext\&pid=S217720612015000200002\&lng=pt\&tlng=pt

Castro, V. R. (2017). Reflexões sobre a saúde mental do estudante universitário: estudo empírico com estudantes de uma instituição publica de ensino superior. Revista Gestão em Foco, 9, 380-401. http://portal.unisepe.com.br/unifia/wpcontent/uploads/sites/10001/2018/06/043_saude_mental. pdf

Costa, A. C. G., \& Vieira M. A. (2000). Protagonismo juvenil: adolescência, educação e participação democrática. Fundação Odebrecht.

Costa, L. B. (2014). Cartografia: uma outra forma de pesquisar. Revista Digital do LAV, 7(2), 66-77. http://dx.doi. org/10.5902/1983734815111

Coulon, A., Santos, G. G., \& Sampaio S. M. R. (2008). A condiç̧̃ão de estudante: a entrada na vida universitária. Edufba.

Coulon, A. (2017). O ofício de estudante: a entrada na vida universitária. Educação e Pesquisa, 43(4), 1239-1250. https://dx.doi.org/10.1590/s1517-9702201710167954

Daltro, M. R., \& Faria, A. A. (2019). Relato de experiência: Uma narrativa cientifica da pós-modernidade. Estudos e Pesquisas em Psicologia, 19(1), 223-237. https://doi. org/10.12957/epp.2019.43015

Daltro, M. R., \& Pondé, M. P. (2017). Internato em psicologia: aprender-a-refletir-fazendo em contextos de prática do SUS. Revista Psicopedagogia, 34(104), 169-179. http://pepsic.bvsalud.org/scielo.php?script=sci_ arttext\&pid=S0103-84862017000200007\&lng=pt\&tlng=pt 
Han, B. C. (2017). Sociedade do cansaço. Vozes.

Igue, É. A., Bariani, I. C. D., \& Milanesi, P. V. B. (2008). Vivência acadêmica e expectativas de universitários ingressantes e concluintes. Psico-USF, 13(2), 155-164. https://dx.doi. org/10.1590/S1413-82712008000200003

Kodjaoglanian, V. L., Benites, C. C. A., Macário, I., Lacoski, M. C. E. K., Andrade, S. M. O., Nascimento, V. N. A, ... Machado, J. L. (2003). Inovando métodos de ensino-aprendizagem na formação do psicólogo. Psicologia: Ciência e Profissão, 23(1), 2-11. https://dx.doi.org/10.1590/S1414$\underline{98932003000100002}$

Luz, F., \& Levandowski, D. C. (2017). A formatura e a inserção no mercado de trabalho: expectativas e sentimentos de formandas em psicologia. Psicologia Argumento, 24(47), 61-72. https://periodicos.pucpr.br/index.php/ psicologiaargumento/article/view/20153/19439

Mercuri, E., \& Polydoro, S. A. J. (2004). Estudante universitário: características e experiências de formação. Cabral Editora e Livraria Universitária.

Melo, S. L., \& Borges, L. O. (2007). A transição da universidade ao mercado de trabalho na ótica do jovem. Psicologia: Ciência e Profissão, 27(3), 376-395. https://dx.doi.org/10.1590/ S1414-98932007000300002

Greenberg N., James A. C., \& Summers C. (2002). Causes and Consequences of Stress. Integrative and Comparative Biology, 42(3), 508-516. https://doi.org/10.1093/ icb/42.3.508

Oku, A. O., Oku, A., Owoaje, E., \& Monjok, E. (2015). An Assessment of Mental Health Status of Undergraduate Medical Trainees in the University of Calabar, Nigeria: A Cross-Sectional Study. Open Access Macedonian Journal of Medical Sciences, 3(2), 356. https://dx.doi.org/10.3889/ oamjims.2015.068

Oliveira, N. R. C., \& Padovani, R. C. (2014). Saúde do estudante universitário: uma questão para reflexão. Ciência \& Saúde Coletiva, 19(3), 995-996. https://dx.doi.org/10.1590/141381232014193.11042012
Padovani, R. C., Neufeld, C. B., Maltoni, J., Barbosa, L. N. F., Souza, W. F., Cavalcanti, H. A. F., ... Lameu, J. N. (2014). Vulnerabilidade e bem-estar psicológicos do estudante universitário. Revista Brasileira de Terapias Cognitivas, 10(1), 02-10. https://dx.doi.org/10.5935/1808-5687.20140002

Papalia, D. E., Olds, S. W., \& Feldman R. D.(2000). Desenvolvimento humano. Artes Médicas Sul.

Papalia, D. E., Olds, S. W., \& Feldman, R. D. (2006). Desenvolvimento humano. Artes Médicas Sul.

Ramos, F. P., Jardim, A. P., Gomes, A. C. P., \& Lucas, J. N. (2018) Desafios na trajetória acadêmica e apoio psicológico ao estudante universitário: contribuições de dois Projetos de Extensão. Revista Guará, 9, 57-67. https://doi.org/10.30712/ guara.v6i9.15783

Sampaio, C. O., \& Queiroz, A. (2019). Entre trilhos e trilhas: relato de experiência da utilização da Aprendizagem Baseada em Problemas em um curso de psicologia. Revista Psicologia, Diversidade e Saúde, 8(1), 49-61. https://doi. org/10.17267/2317-3394rpds.v8i1.2213

Silva, R. M., \& Daltro, M. R. (2018). Experiências de sofrimento e enfrentamento no ingressar ao ensino superior: narrativa autobiográfica. Revista Psicologia, Diversidade e Saúde, 7(3), 433-441. https://doi.org/10.17267/2317-3394rpds. v7i3.1930

Soares, A. (2018). Sociedade, contemporaneidade e sofrimento psíquico. Percurso Livre em Psicanalise. http://www. percursoempsicanalise.com.br/artigo-sociedadecontemporaneidade-e-sofrimento-psiquico/

Sousa, F. C. (2007). O que é "ser adulto": as práticas e representações sociais sobre o que é "ser adulto" na sociedade portuguesa. Revista Eletrônica Acolhendo a Alfabetização nos Países de Língua Portuguesa, 1(2), 56-69. https://doi.org/10.11606/issn.1980-7686.v1i2p56-69

Souza, L. K., Lourenço, E., \& Santos, M. R. G. (2016). Adaptação à universidade em estudantes ingressantes na graduação em psicologia. Psicologia da Educação, (42), 35-48. https:// dx.doi.org/10.5935/2175-3520.20150023

Yamamoto, O. H., \& Gouveia, V. V. (2002). Construindo a psicologia brasileira: desafios da ciência e prática psicológica. Casa do Psicólogo. 